\title{
Influência da mastite nas frações eletroforéticas do colostro de vacas da raça Holandesa ${ }^{1}$
}

\author{
Guilherme G.F. Santos ${ }^{2}$, Maurício Deschk ${ }^{2}$, André K.G. Silva ${ }^{3}$, Tatiana S. Poló ${ }^{2}$, \\ Marcia Marinho ${ }^{4}$, Juliana R. Peiró ${ }^{5}$ e Francisco L.F. Feitosa ${ }^{5 *}$
}

\begin{abstract}
Santos G.G.F., Deschk M., Silva A.K.G., Poló T.S., Marinho M., Peiró J.R. \& Feitosa F.L.F. 2018. [Influence of mastitis on electrophoretic fractions of colostrum from Holstein cows.] Influência da mastite nas frações eletroforéticas do colostro de vacas da raça Holandesa. Pesquisa Veterinária Brasileira 38(3):430-435. Departamento de Clínica, Cirurgia e Reprodução Animal, Faculdade de Medicina Veterinária de Araçatuba, Universidade Estadual Paulista "Júlio de Mesquita Filho", Rua Clóvis Pestana 793, Jardim Dona Amélia, Araçatuba, SP 16050-680, Brazil. E-mail: leydsonf@fmva.unesp.br

The aim of this study was to evaluate the protein fractions in colostral secretions of cows affected by mastitis immediately after calving. Therefore, 30 Holstein cows were divided into three groups: Group I (GI) composed of ten multiparous cows calving without mastitis; Group II (GII) composed of ten multiparous cows calving with subclinical mastitis, and Group III (GIII) composed of ten multiparous cows calving with mastitis. The concentration of immunoglobulin A (IgA), lactoferrin (LF), albumin, immunoglobulin G (IgG), $\beta$-lactoglobulin $(\beta-\mathrm{Lg})$ and $\alpha$-lactoalbumin $(\alpha-\mathrm{La})$ was determined by sodium dodecyl sulphate-polyacrylamide gel electrophoresis (SDS-PAGE). It was found that the IgG, LF and albumin vary among glands of subclinical and clinical mastitis and healthy and that the presence of a bacteria in the mammary gland was the key role for changing of the pattern of serum protein source.

INDEX TERMS: Mastitis, electrophoretic fractions, colostrum, Holstein cows, cattle, SDS-PAGE, clinics.
\end{abstract}

RESUMO.- 0 objetivo desse estudo foi o de avaliar as frações proteicas em secreções colostrais de vacas acometidas por mastite clínica imediatamente após o parto. Para tanto, foram utilizadas 30 vacas da raça Holandesa distribuídas em três grupos, a saber: Grupo I (GI)- 10 vacas pluríparas sadias, Grupo II (GII) 10 vacas pluríparas que pariram com mastite assintomática e Grupo III (GIII) 10 vacas pluríparas que pariram com mastite clínica. Foram avaliadas as concentrações de imunoglobulina

\footnotetext{
${ }^{1}$ Recebido em 27 de julho de 2016.

Aceito para publicação em 6 de fevereiro de 2017.

${ }^{2}$ Pós-Graduando em Ciência Animal, Faculdade de Medicina Veterinária, Universidade Estadual Paulista (Unesp), Rua Clóvis Pestana 793, Jardim Dona Amélia, Araçatuba, SP 16050-680, Brasil.

${ }^{3}$ Graduando, Faculdade de Medicina Veterinária, Universidade Estadual Paulista, Rua Clóvis Pestana 793, Jardim Dona Amélia, Araçatuba, SP 16050-680. Bolsista de Iniciação Científica do CNPq.

${ }^{4}$ Docente, Departamento de Apoio à Produção e Saúde Animal, Faculdade de Medicina Veterinária, Universidade Estadual Paulista, Rua Clóvis Pestana 793, Jardim Dona Amélia, Araçatuba, SP 16050-680.

${ }^{5}$ Departamento de Clínica, Cirurgia e Reprodução Animal, Faculdade de Medicina Veterinária, Universidade Estadual Paulista, Rua Clóvis Pestana 793, Jardim Dona Amélia, Araçatuba, SP 16050-680. *Autor para correspondência: leydsonf@fmva.unesp.br
}

a (IgA), lactoferrina (LF), albumina, imunoglobulina G (IgG), $\beta$-lactoglobulina $(\beta-\operatorname{Lg})$ e $\alpha$-lactoalbumina $(\alpha$-La) por meio da eletroforese em gel de poliacrilamida contendo dodecil sulfato de sódio (SDS-PAGE).Observou-se que a IgG, LF e a albumina variaram entre as glândulas com mastite assintomática e clínica quando comparadas às glândulas sadias, e que a presença de um único microrganismo é capaz de promover alterações no proteinograma, com ou sem manifestações clínicas na glândula mamária.

TERMOS DE INDEXAÇ̃̃: Mastite, frações eletroforéticas, colostro, vacas Holandesas, bovino, SDS-PAGE, clínica.

\section{INTRODUÇÃO}

A mastite é a principal doença infecciosa que acomete o rebanho leiteiro no mundo (Barkema et al. 2009). Essa enfermidade pode ocorrer em qualquer fase da lactação, inclusive no pós-parto imediato. A ocorrência da mastite nesse período se deve a maior vulnerabilidade às infecções em virtude da debilidade do sistema imunológico atribuída a alterações endócrinas e metabólicas que se iniciam no período seco. Dessa forma, durante o referido período, há maior suscetibilidade aos 
diferentes processos infecciosos, o que pode impactar em mudanças no colostro e/ou nos quartos mamários infectados (Ingvartsen \& Moyes 2015).

A infecção da glândula mamária ocasiona profundas mudanças nos constituintes lácteos, alterando as características físico-químicas e organolépticas do colostro (Birgel 2014). Durante esse evento, há uma maior permeabilidade os vasos sanguíneos o que permite a passagem dos constituintes séricos para o interior do úbere (Burton \& Erskine 2003). Quando as infecções intramamárias ocorrem durante o período seco, ocorre uma perda de até $40 \%$ do potencial do quarto na lactação subsequente (Langoni et al. 2000).

O colostro bovino é constituído por inúmeras proteínas, uma parte delas é formada no interior da própria glândula mamária, como, por exemplo, a $\beta$-lactoglobulina e a $\alpha$-lactoalbumina. Outra é originada da corrente sanguínea, como a IgG e a albumina (Rocha 2010). A IgG é essencial para os animais recém-nascidos e sua aquisição ocorre exclusivamente por meio da ingestão do colostro, uma vez que a placenta dos bovinos impede a passagem dessas proteínas para os bezerros durante a gestação (Godden 2008). Nesse aspecto, a secreção colostral deve conter número ínfimo ou nulo de microrganismos para que não haja transferência para essa categoria animal (Johnson et al. 2007).

A determinação do proteinograma por meio da técnica de eletroforese em gel de poliacrilamida contendo dodecil sulfato de sódio (SDS-PAGE) é útil para a identificação e quantificação das frações protéicas presentes na secreção láctea de fêmeas bovinas. Ao longo dos anos essa técnica tem sido usada por diferentes pesquisadores para o diagnóstico de algumas enfermidades inflamatórias, dentre elas, a mastite (Sant'Ana 2004, Rocha 2010, Raimondo et al. 2013). Portanto, o objetivo desse trabalho foi avaliar o colostro nas primeiras 48 horas após a parição, oriundo de vacas sadias e acometidas por mastite assintomática e sintomática utilizando a técnica de eletroforese SDS-PAGE, de modo a estabelecer as possíveis alterações na concentração das frações proteicas.

\section{MATERIAL E MÉTODOS}

Amostras de colostro foram obtidas de quartos mamários individuais de 30 vacas da raça Holandesa criadas a pasto e oriundas de uma mesma propriedade, localizada na região de Araçatuba/SP. A seleção dos animais foi baseada no exame físico e no histórico com relação à saúde da glândula mamária e à presença de mastite em um ou mais períodos de lactação. Para tanto, os animais foram divididos em três grupos, a saber: Grupo I (GI): composto por secreções colostrais de dez vacas pluríparas com glândulas mamárias sadias e com isolamento bacteriológico negativo; Grupo II (GII): constituído por secreções colostrais de vacas pluríparas com mastite assintomática, caracterizada por elevada contagem de células somáticas (CCS), isolamento microbiológico positivo e escores positivos ao California Mastitis Test (CMT); e, Grupo III (GIII): composto por secreções colostrais de dez vacas pluríparas com mastite sintomática, apresentando alterações físicas da glândula mamária, presença de alterações macroscópicas na secreção colostral e isolamento microbiológico. As amostras do grupo I foram obtidas do quarto posterior direito e, nos demais grupos (Grupos II e III) do quarto mamário que possuía maiores CCS e reação ao CMT (Mastite assintomática) associadas à intensa alteração física do quarto mamário e da secreção colostral à avaliação (Mastite sintomática), respectivamente.

As amostras foram coletadas imediatamente após o parto $(0 \mathrm{~h})$, bem como às 24 horas e às 48 horas do referido evento. Após o preparo dos animais para a ordenha, três jatos de leite eram desprezados em recipientes de fundo escuro, para melhor observar as características macroscópicas da secreção colostral. Posteriormente seguia-se a coleta de cerca de $3 \mathrm{~mL}$ de colostro em tubos do tipo Falcon estéril para o exame microbiológico, precedido por assepsia do teto, utilizando-se algodão embebido em álcool $70^{\circ} \mathrm{GL}$ (International Dairy Federation 1981). Em seguida, foram obtidos $40 \mathrm{~mL}$ de colostro destinado à separação do soro lácteo para a eletroforese. As amostras foram levadas ao laboratório em caixas de isopor refrigeradas com gelo reciclável para processamento.

O cultivo das amostras destinadas ao isolamento microbiológico foi realizado no Laboratório de Bacteriologia e Micologia do Departamento de Apoio, Produção e Saúde Animal da Faculdade de Medicina Veterinária de Araçatuba. Para tanto, as amostras foram semeadas em meio de ágar sangue de ovino desfibrinado $5 \%$ e ágar MacConkey e incubadas a $37^{\circ} \mathrm{C}$, sendo as leituras do aspecto das colônias realizadas após 24, 48 e 72 horas de incubação. Observouse a positividade ao teste de coagulação bem como a morfologia das colônias, anotando-se características com relação ao tamanho, forma, produção ou não de pigmento, bem como a presença de hemólise. Foram consideradas como cultura positiva quando havia o crescimento de pelo menos três colônias idênticas em um mesmo meio de cultivo, exceto para $S$. aureus, que se considerou como positiva a partir do crescimento de uma colônia (National Mastitis Council 1999, Quinn et al. 2005).

Para a obtenção do soro lácteo adicionou-se á secreção láctea, solução de renina (Coalho Estrella ${ }^{\circledR}$ ), referente a 10\% do volume total presente no tubo, permanecendo esta em banho-maria a $37^{\circ} \mathrm{C}$ por 20 minutos até a retração do coágulo. Posteriormente, foram processadas em centrífuga refrigerada a $4200 \mathrm{G}$ por 20 minutos a $15^{\circ} \mathrm{C}$ (Rocha 2010 ). Após esse procedimento, foi obtida uma solução trifásica, sendo removida a gordura posicionada em porção superior, com auxílio de uma bomba de vácuo; a porção intermediária, correspondendo ao soro lácteo, foi aliquotada em microtubos com capacidade de $1,5 \mathrm{~mL}$, e armazenada a $-20^{\circ} \mathrm{C}$ até o momento das análises laboratoriais, posteriormente realizadas no Centro de Pesquisa do Departamento de Clínica, Cirurgia e Reprodução Animal da Faculdade de Medicina Veterinária de Araçatuba, Unesp.

Para o fracionamento eletroforético em SDS-PAGE utilizou-se a técnica proposta por Laemmli (1970). As frações foram mensuradas por meio de programa computadorizado (Image Quant TL GE healthcare). Para a identificação das frações proteicas do soro lácteo, foram utilizadas como padrões proteínas de baixo peso molecular (entre 10 e $250 \mathrm{KDa}$ ) além das proteínas purificadas lactoferrina (LF), albumina sérica, imunoglobulina G bovina (IgG), imunoglobulina A humana (IgA), $\beta$ - lactoglobulina $(\beta$-Lg) e $\alpha$-lactoalbumina ( $\alpha$-La) da marca Sigma ${ }^{\circledR}$.

Os dados foram testados quanto à normalidade e à homogeneidade. As variáveis foram submetidas à análise de variância, com medidas repetidas, sendo as médias comparadas por meio do teste de KruskalWallis para comparar os grupos em cada momento e o teste de Friedman para comparar os momentos em cada grupo, seguido do teste de Dunn para comparações múltiplas. As análises estatísticas foram efetuadas empregando-se o programa SAS (Statistical Analysis System) (Zar 1999). 


\section{RESULTADOS}

0 resultado do exame bacteriológico encontra-se apresentado no Quadro 1. Não se observou crescimento bacteriano em nenhuma amostra de secreção láctea do grupo I (GI). Das 10 amostras obtidas de glândulas mamárias do grupo II (GII), constatou-se o crescimento de Streptococcus sp. em $20 \%$ (2/10 amostras), e de S. intermedius em 50\% (5/10 mostras) delas. Das glândulas do GIII, o Streptococcus sp. foi isolado em 40\% (4/10 amostras). A maioria (8/10) das amostras do grupo II possuía alteração de viscosidade. Das 10 secreções colostrais avaliadas no grupo III (GIII) verificou-se a presença de grumos em seis amostras. Verificaram-se, também, estrias de sangue em uma amostra e grande quantidade de pus em outras três secreções. Staphylococcus sp. foi isolado em 50\% (5/10 amostras) das secreções cultivadas, sendo que S. intermedius foi isolado em três glândulas, S. aureus em uma e, em outra foi observado Staphylococcus coagulase negativa (ECN). Em nenhuma secreção colostral do GII e GIII houve isolamento de mais de um agente etiológico. Em ambos os grupos, $S$. intermedius foi o agente mais frequentemente isolado $(8 / 20)$.

Os teores de IgA e IgG estão expressos no Quadro 2. Não foi constatada diferença significativa entre os grupos quanto às concentrações de IgA no soro lácteo durante o período de observação experimental. Suas concentrações foram significativamente maiores no momento do parto. Com a evolução da lactação, houve redução gradual até o último momento do estudo (48 horas). 0 teor de IgG no soro lácteo foi superior nos animais do GIII quando comparado ao GI no momento do parto. As maiores concentrações desta proteína foram observadas logo após a parição, seguidas de redução gradativa. No GII e GIII os teores mínimos foram constatados às 24 horas do período experimental, diferindo do GI, que demonstrou redução gradativa nas primeiras 48 horas de observação. Porém, a concentração dessa proteína foi maior às 48 horas do período experimental no GIII quando comparado ao GI.

As concentrações de albumina foram superiores, imediatamente após o parto, nos animais do GII e GIII quando comparados ao GI, conforme exposto no Quadro 3. A concentração da referida fração se manteve superior no colostro dos animais do GIII em relação ao do GI em todos os momentos, não diferindo, contudo, do GII, no momento do parto. A LF apresentou maiores concentrações nas secreções lácteas do GIII em relação ao do GII, no momento do parto, e àquelas do GI, às 48 horas de estudo. Houve um declínio com o passar do período experimental, em suas concentrações, principalmente no GI e GII. Esta se manteve inalterada às 24 horas e 48 horas no GIII.

A $\beta$-Lg não apresentou diferenças significativas entre os grupos e momentos estudados, conforme descrito no quadro 4. A $\alpha$-LA apresentou redução gradativa em suas concentrações somente no GI. No GII e GIII as concentrações se mantiveram constantes ao longo do período experimental. No entanto os animais do GI apresentaram concentrações maiores dessa proteína no momento do parto quando comparado aos demais grupos. E esses não apresentaram diferenças significativas entre si nas primeiras 24 horas de observação.

\section{DISCUSSÃO}

A presença de microrganismos na secreção colostral observada imediatamente após o parto foi relatada por vários autores (Sargeant et al. 2001, Schrick et al. 2001, Reis et al. 2016).

Quadro 1. Identificação microbiológica (no de agentes isolados) em amostras de colostro de glândulas mamárias de fêmeas bovinas Holandesas com mastite assintomática $(n=10)$ e clínica (n=10), Araçatuba/SP, 2013

\begin{tabular}{|c|c|c|}
\hline Grupo & GII $(n=10)$ & $\operatorname{GIII}(n=10)$ \\
\hline \multirow[t]{5}{*}{ Isolamento (№) } & Streptococcus sp. (2) & Streptococcus sp. (4) \\
\hline & Staphylococcus intermedius (5) & Staphylococcus intermedius (3) \\
\hline & Staphylococcus aureus (1) & Staphylococcus coagulase negativa(1) \\
\hline & Trueperella sp. (1) & Staphylococcus aureus (1) \\
\hline & Bastonetes Gram - (1) & Bacillus cereus (1) \\
\hline
\end{tabular}

Um total de 40 amostras submetidas ao exame bacteriológico (GII e GIII sem crescimento bacteriano).

Quadro 2. Valores médios $(\bar{X})$, desvios-padrão (S) e mediana (Md) do teor de imunoglobulina A (mg/dL) e Imunoglobulina G $(\mathrm{mg} / \mathrm{dL})$ no colostro de glândulas mamárias sadias vacas pluríparas saudáveis (GI=10), vacas com mastite assintomática (GII, $\mathrm{n=10)}$ e vacas com mastite clínica (GIII, n=10), imediatamente após o parto (0h), às 24 horas e às 48 horas, Araçatuba/SP, 2013

\begin{tabular}{|c|c|c|c|c|c|c|c|}
\hline & \multirow{3}{*}{ Grupo } & \multicolumn{6}{|c|}{ Momentos estudados } \\
\hline & & \multicolumn{2}{|c|}{$0 \mathrm{~h}$} & \multicolumn{2}{|c|}{$24 \mathrm{~h}$} & \multicolumn{2}{|c|}{$48 \mathrm{~h}$} \\
\hline & & $(\bar{X} \pm S)$ & Md & $(\bar{X} \pm \mathrm{S})$ & Md & $(\bar{X} \pm \mathrm{S})$ & Md \\
\hline \multirow[t]{3}{*}{$\operatorname{IgA}$} & GI & $636,30 \pm 162,30$ & $671,8 \mathrm{Aa}$ & $130,30 \pm 79,88$ & $111,4 \mathrm{ABa}$ & $34,15 \pm 13,6$ & $31,67 \mathrm{Bb}$ \\
\hline & GII & $426,4 \pm 291,5$ & $316,5 \mathrm{Aa}$ & $216,5 \pm 307,1$ & $110,6 \mathrm{ABa}$ & $29,22 \pm 15,74$ & $26,58 \mathrm{Bb}$ \\
\hline & GIII & $492,0 \pm 288,7$ & 463Aa & $198,2 \pm 198,6$ & $131,6 \mathrm{ABa}$ & $90,29 \pm 46,23$ & $87,66 \mathrm{Ba}$ \\
\hline \multirow[t]{3}{*}{$\operatorname{IgG}$} & GI & $8374 \pm 1142$ & $8026 \mathrm{Ab}$ & $2869 \pm 1522$ & $2843 \mathrm{Ba}$ & $1033 \pm 340$ & $1171 \mathrm{Cb}$ \\
\hline & GII & $9387 \pm 2706$ & 9742Aab & $2672 \pm 999,3$ & 2689Ba & $1359 \pm 376,5$ & $1277 \mathrm{Cab}$ \\
\hline & GIII & $11939 \pm 2824$ & $12674 \mathrm{Aa}$ & $4137 \pm 3038$ & $3325 \mathrm{BCa}$ & $2140 \pm 936,6$ & $1731 \mathrm{Ca}$ \\
\hline
\end{tabular}

Medianas seguidas de letras distintas, maiúscula na linha e minúscula na coluna, diferem entre si (p<0,05) pelo teste de Kruskal-Wallis e de comparações múltiplas de Dunn. 
Quadro 3. Valores médios $(\bar{X})$, desvios-padrão (S) e mediana (Md) do teor de Albumina (mg/dL) e lactoferrina (mg/dL) no colostro de glândulas mamárias sadias vacas pluríparas saudáveis $(\mathrm{GI}=10)$, vacas com mastite assintomática (GII, n=10) e vacas com mastite clínica (GIII, n=10), imediatamente após o parto (0h), às 24 horas e às 48 horas, Araçatuba/SP, 2013

\begin{tabular}{|c|c|c|c|c|c|c|c|}
\hline & \multirow{3}{*}{ Grupo } & \multicolumn{6}{|c|}{ Momentos estudados } \\
\hline & & \multicolumn{2}{|c|}{$0 \mathrm{~h}$} & \multicolumn{2}{|c|}{$24 \mathrm{~h}$} & \multicolumn{2}{|c|}{$48 \mathrm{~h}$} \\
\hline & & $(\bar{X} \pm S)$ & $\mathrm{Md}$ & $(\bar{X} \pm S)$ & $\mathrm{Md}$ & $(\bar{X} \pm S)$ & $\mathrm{Md}$ \\
\hline \multirow[t]{3}{*}{ Albumina } & GI & $591,2 \pm 138,8$ & $574,9 \mathrm{Ab}$ & $196,2 \pm 191,6$ & $142,9 \mathrm{ABb}$ & $36,32 \pm 13,16$ & $30,42 \mathrm{Bb}$ \\
\hline & GII & $1128 \pm 396,8$ & $998,3 \mathrm{Aa}$ & $409,2 \pm 248,5$ & $344,8 \mathrm{Bab}$ & $218,7 \pm 134,6$ & $194,6 \mathrm{Bb}$ \\
\hline & GIII & $1680 \pm 603,2$ & $1560 \mathrm{Aa}$ & $733,7 \pm 434,8$ & $840,8 \mathrm{BCa}$ & $713,8 \pm 652$ & $440,3 \mathrm{Ca}$ \\
\hline Lactoferrina & GI & $872 \pm 177,3$ & $810,8 \mathrm{Aab}$ & $288,2 \pm 143$ & $293,4 \mathrm{Ba}$ & $85,42 \pm 41,76$ & $79,2 \mathrm{Cb}$ \\
\hline
\end{tabular}

Medianas seguidas de letras distintas, maiúscula na linha e minúscula na coluna, diferem entre si $(p<0,05)$ pelo teste de Kruskal-Wallis e de comparações múltiplas de Dunn.

Quadro 4. Valores médios ( $\bar{X}$ ), desvios-padrão (S) e mediana (Md) do teor de $\alpha$ - Lactoalbumina e $\beta$-Lactoglobulina (mg/dL) no colostro de glândulas mamárias sadias vacas pluríparas saudáveis (GI=10), vacas com mastite assintomática (GII, $n=10)$ e vacas com mastite clínica (GIII, n=10), imediatamente após o parto (0h), às 24 horas e às 48 horas, Araçatuba/SP, 2013

\begin{tabular}{|c|c|c|c|c|c|c|c|}
\hline & \multirow[b]{2}{*}{ Grupo } & \multicolumn{6}{|c|}{ Momentos estudados } \\
\hline & & \multicolumn{2}{|c|}{$0 \mathrm{~h}$} & \multicolumn{2}{|c|}{$24 \mathrm{~h}$} & \multicolumn{2}{|c|}{$48 \mathrm{~h}$} \\
\hline \multirow[t]{2}{*}{$\alpha$-Lactoalbumina } & GI & $608,5 \pm 199,7$ & $615,1 \mathrm{Aa}$ & $258 \pm 112,7$ & $244,7 \mathrm{BCa}$ & $162,6 \pm 65,69$ & $170,8 \mathrm{Cb}$ \\
\hline & GIII & $226,9 \pm 99,19$ & $208,8 \mathrm{Ab}$ & $299,6 \pm 194,9$ & $232,0 \mathrm{Aa}$ & $336,5 \pm 21,34$ & $264,4 \mathrm{Aa}$ \\
\hline$\beta$-Lactoglobulina & GI & $3039 \pm 824,4$ & 3287Aa & $1356 \pm 737,3$ & 2200BCa & $643,7 \pm 247,4$ & $553,4 \mathrm{Ca}$ \\
\hline
\end{tabular}

Medianas seguidas de letras distintas, maiúscula na linha e minúscula na coluna, diferem entre si $(\mathrm{p}<0,05)$ pelo teste de Kruskal-Wallis e de comparações múltiplas de Dunn.

Segundo Sargeant et al. (2001) os microrganismos mais comumente isolados, nesse período, em secreções colostrais de glândulas com mastite sintomática, são Staphylococcus coagulase negativa, Staphylococcus aureus, Escherichia coli e Streptococcus sp. Em 50\% das glândulas avaliadas houve o crescimento de Staphylococcus sp. Dentre os microrganismos isolados houve uma maior ocorrência de Staphylococcus intermedius (3/5 amostras), quando comparado ao $S$. aureus (1/5 amostras), ambos Staphylococcus coagulase Positivo (ECP). Resultados similares foram obtidos por Voltolini et al. (2001) que observaram que $49 \%$ dos microrganismos isolados de quartos mamários de vacas Holandesas era de ECP. Segundo Urech et al. (1999) as espécies de Streptococcus spp. são os maiores causadores da mastite assintomática. No entanto, Schrick et al. (2001) denotaram majoritariamente Staphylococcus sp. como os principais agentes causadores de mastite assintomática no pós-parto imediato. 0 mesmo foi observado nesse estudo para o GII, que assim como para o GIII, S. intermedius foi o principal agente isolado.

0 processo inflamatório na glândula mamária é responsável por inúmeras alterações dos constituintes da secreção láctea (Sant'Ana 2004, Ferdowski Nia et al. 2010). Segundo Maunsell etal. (1998) a mastite causa o aumento da passagem de IgG para o interior da glândula mamária em virtude de três características: alteração da barreira entre a corrente sanguínea e a glândula mamária; aumento do transporte seletivo de IgG para o interior do úbere e, por fim, diminuição da produção do volume de leite, propiciando maior concentração de IgG. No presente estudo as secreções colostrais do GIII apresentaram resultados superiores ao do GI no momento do parto, confirmando a assertiva supracitada. Independentemente da presença de um processo inflamatório na glândula mamária, as concentrações de IgG foram declinando ao longo das 48 horas após o parto. As concentrações de IgG mostraram-se superiores nas secreções lácteas de vacas com mastite (Grupo III) em todos os momentos avaliados. As vacas com glândulas mamárias sadias possuíam os menores teores de IgG, enquanto àquelas com mastite assintomática apresentaram valores intermediários aos obtidos nos Grupos I e III, evidenciando-se, que, mesmo na ausência de manifestação de processo inflamatório, a invasão da glândula mamária por determinado microrganismo, é capaz, por si só, de promover o influxo de IgG para o interior da glândula mamária acometida, contrariando, portanto, as descrições de Holdaway et al. (1996) quando afirmavam que somente na vigência de um processo inflamatório agudo tal situação ocorreria.

Diferentemente da IgG, a IgA não apresentou diferença significativa entre os grupos nas primeiras 24 horas de vida, o que é plenamente justificável pelo fato de a IgA representar somente $5 \%$ do total de imunoglobulinas presentes no colostro 
dos ruminantes. Por encontrar-se em pequenas concentrações, as possíveis alterações em virtude de uma inflamação da glândula mamária mostram-se pouco significantes do ponto de vista clínico (Johnson et al. 2007).

Além das imunoglobulinas, os neutrófilos também migram da corrente circulatória para o interior do úbere durante os episódios de mastite, recrutados pelas citocinas (Pessoa etal. 2012). A LF é produzida pelos neutrófilos presentes na secreção colostral. No colostro isento de microrganismos a concentração dessa proteína é baixa, sendo menor ainda no leite normal. Entretanto, quando a glândula mamária sofre infecção bacteriana a liberação dessa proteína ocorre em grande intensidade (Kawai et al. 2007). Os valores de lactoferrina foram significativamente maiores nos animais do GIII quando comparados ao GII, logo após o parto. Esses teores estão de acordo com os resultados obtidos por Kawai et al. (1999). Segundo esse autor essa diferença está pautada na intensidade do processo inflamatório. No entanto, o GI também apresentou concentrações similares ao GIII, sendo essas compatíveis com os teores referendados por Sant'Ana (2004). A LF pode variar conforme o número de lactações, contagem de células somáticas e produção leiteira (Hagiwara et al. 2003). Portanto, essa imensa gama de variáveis pode ter contribuído para a ausência de diferença entre o GI e o GIII.

A albumina do soro lácteo é geneticamente idêntica àquela encontrada no sangue. Durante o processo inflamatório essa proteína escoa pelas junções laterais das células epiteliais dos vasos sanguíneos para o interior da glândula mamária (Nguyen \& Neville 1998). Entretanto, alguns pesquisadores acreditam que essa proteína faça parte da imunidade inata da glândula mamária (Shamay et al. 2005). 0 elevado teor de albumina no GII e GIII quando comparados ao GI no momento do parto está intimamente ligado à presença de microrganismos na glândula mamária. Segundo Bannerman et al. (2003) as concentrações de albumina aumentam tanto em episódios de mastite sintomática quanto assintomática. Shamay et al. (2005) relataram que a presença de toxina é responsável por um aumento na síntese de albumina pelas próprias células da glândula mamária. Entretanto, o mecanismo utilizado por essas células é ainda desconhecido. Essa proteína também participa da defesa do úbere, apresentando função antioxidante, por agir sobre os radicais livres oriundos da inflamação (Bounous 2000). As alterações causadas pelo processo inflamatório nos quartos mamários dos animais do GIII foram responsáveis por maiores concentrações dessa proteína em todos os momentos avaliados quando comparado ao GI.

A $\alpha$-La, assim como a $\beta$-Lg, é uma fração proteica sintetizada pela glândula mamária. A $\alpha$-La apresenta papel essencial na biossíntese da lactose sendo de importância para o neonato, por isso sua concentração é elevada no colostro de animais sadios (Farrell et al. 2004). Os resultados avaliados nessa pesquisa denotaram uma menor concentração dessa proteína em glândulas acometidas por mastite assintomática e sintomática quando comparadas às glândulas sadias. Esses resultados concordam com Boehmer et al. (2010) que citam que as alterações causadas pelo processo inflamatório nas células do tecido mamário poderiam prejudicar a produção dos constituintes lácteos formados no interior da mama. Segundo esses autores, secreções lácteas com cultivo bacteriano positivo apresentavam valores inferiores quando comparado às glândulas sadias, como foi também observado no presente estudo. Segundo Sordillo et al. (1989) os quadros de mastite sintomática durante a colostrogênese causados por Sthapylococcus sp. causam lesões no epitélio mamário com queda acentuada da $\alpha$-La. Segundo Anderson \& Andrews (1977), essa fração sofre queda natural após a instauração do processo infeccioso e aumenta 24 horas após este. Essa característica foi observada nos animais do GII e GIII que apresentaram valores semelhantes às glândulas do GI no momento supracitado.

A ausência de diferenças significativas entre as glândulas sadias e as acometidas por mastite assintomática e sintomática para os valores de $\beta$-Lg foram similares aos dados de Sant'Ana (2004). Caffin et al. (1985) observaram que os valores de $\beta$-Lg não se alteraram em secreções lácteas com contagem elevada de células somáticas e cultivo bacteriológico positivo de ECN. O grande número de Staphylococcus sp. isolado no GII e GIII nos indica que essa espécie de bactéria não foi capaz de causar alterações nessa proteína de origem glandular. No entanto, Boehmer et al. (2010), observaram declínio dessa fração proteica na secreção láctea de animais com mastite experimental induzida por cepas patogênicas de E. coli, o que corrobora a afirmação supracitada.

\section{CONCLUSÕES}

As concentrações de IgG, albumina e lactoferrina encontram-se elevadas em secreções lácteas de vacas com mastites assintomática e sintomática.

A presença do microrganismo na glândula mamária é por si só capaz de alterar alguns constituintes do proteinograma do colostro de vacas da raça Holandesa.

Agradecimentos.- À Fundação de Amparo à Pesquisa do Estado de São Paulo (FAPESP) pelo auxílio financeiro e pela bolsa de estudos (Procs.2010/12256-1 e 2010/12229-4).

\section{REFERÊNCIAS}

Anderson M. \& Andrews A.T. 1977. Progressive changes in individual protein concentrations associated with high somatic cell counts. J. Dairy Res. 44(2):223-235. http://dx.doi.org/10.1017/S002202990002015X. PMid:332723.

Bannerman D.D., Paape M.J., Hare W.R. \& Sohn E.J. 2003. Increased levels of LPS-binding protein in bovine blood and milk following bacterial lipopolysaccharide challenge. J. Dairy Sci. 86(10):3128-3137. http://dx.doi. org/10.3168/jds.S0022-0302(03)73914-9. PMid:14594231.

Barkema H.W., Green M.J., Bradley A.J. \& Zadoks R.N. 2009. Invited review: the role of contagious disease in udder health. J. Dairy Sci. 92(10):4717-4729. http://dx.doi.org/10.3168/jds.2009-2347. PMid:19762787.

Birgel E.H. 2014. Semiologia da glândula mamária de ruminantes, p.300331. In: Feitosa F.L. (Ed.), Semiologia Veterinária: a arte do diagnóstico. Roca, São Paulo.

Boehmer J.L., Ward J.L., Peters R.R., Shefcheck K.J., McFarland M.A. \& Bannerman D.D. 2010. Proteomic analysis of the temporal expression of bovine milk proteins during coliform mastitis and label-free relative quantification. J. Dairy Sci. 93(2):593-603. http://dx.doi.org/10.3168/ jds.2009-2526. PMid:20105531.

Bounous G. 2000. Whey protein concentrate (WPC) and glutathione modulation in cancer treatment. Anticancer Res. 20(6C):4785-4792. PMid:11205219.

Burton J.L. \& Erskine R.J. 2003. Immunity and mastitis: Some new ideas for an old disease. Vet. Clin. N. Am., Food Anim. Pract. 19(1):1-45, v. http:// dx.doi.org/10.1016/S0749-0720(02)00073-7. PMid:12682934. 
Caffin J.P., Poutrel B. \& Rainard P. 1985. Physiological and pathological factors influencing bovine $\alpha$-lactalbumin and $\beta$-lactoglobulin concen trations in milk. J. Dairy Sci. 68(5):1087-1094. http://dx.doi.org/10.3168/jds.S00220302(85)80933-4. PMid:3842846.

Farrell Jr H.M., Jimenez-Flores R., Bleck G.T., Brown E.M., Butler J.E., Creamer L.K., Hicks C.L., Hollar C.M., Ng-Kwai-Hang K.F. \& Swaisgood H.E. 2004. Nomenclature of the proteins of cows' milk: sixth revision. J. Dairy Sci. 87(6):1641-1674. http://dx.doi.org/10.3168/jds.S0022-0302(04)733196. PMid:15453478.

Godden S. 2008. Colostrum management for dairy calves. Vet. Clin. N. Am., Food Anim. Pract. 24(1):19-39. http://dx.doi.org/10.1016/j.cvfa.2007.10.005. PMid:18299030.

Hagiwara S., Kawai K., Anri A. \& Nagahata H. 2003. Lactoferrin concentrations in milk from normal and subclinical mastitic cows. J. Vet. Med. Sci. 65(3):319323. http://dx.doi.org/10.1292/jvms.65.319. PMid:12679560.

Holdaway R.J., Holmes C.W. \& Steffert I.J. 1996. A comparison of indirect methods for diagnosis of subclinical intramammary infection in lactating dairy cows. Aust. J. Dairy Technol. 51(2):64-71.

Ingvartsen K.L. \& Moyes K.M. 2015. Factors contributing to immunosuppression in the dairy cow during the periparturient period. Jpn. J. Vet. Res. 63(1, Suppl.1):15-24. PMid:25872323.

International Dairy Federation. 1981. Laboratory methods for use in mastitis work. Bull. Int. Dairy Fed. 132:27p.

Johnson J.L., Godden S.M., Molitor T., Ames T. \& Hagman D. 2007. Effects of feeding heat-treated colostrum on passive transfer of immune and nutritional parameters in neonatal dairy calves. J. Dairy Sci. 90(11):5189-5198. http:// dx.doi.org/10.3168/jds.2007-0219. PMid:17954759.

Kawai K., Hagiwara S., Anri A. \& Nagahata H. 1999. Lactoferrin concentration in milk of bovine clinical mastitis. Vet. Res. Commun. 23(7):391-398. http:// dx.doi.org/10.1023/A:1006347423426. PMid:10598071.

Kawai K., Shimazaki K., Higuchi H. \& Nagahata H. 2007. Antibacterial activity of bovine lactoferrin hydrolysate against mastitis pathogens and its effect on superoxide production of bovine neutrophils. Zoonoses Public Health 54(3/4):160-164. http://dx.doi.org/10.1111/j.1863-2378.2007.01031.x. PMid:17456148.

Laemmli U.K. 1970. Cleavage of structural proteins during the assembly of the head of bacteriophage T4. Nature 227(5259):680-685. http://dx.doi. org/10.1038/227680a0. PMid:5432063.

Langoni H., Araújo W.N., Silva A.V. \& Souza L.C. 2000. Tratamento da mastite bovina com amoxacilina e enrofloxacina bem como a sua associação. Arqs Inst. Biológico, São Paulo, 67(2):177-180.

Maunsell F.P., Morin D.E., Constable P.D., Hurley W.L., McCoy G.C., Kakoma I. \& Isaacson R.E. 1998. Effects of mastitis on the volume and composition of colostrums produced by Holstein cows. J. Dairy Sci. 81(5):1291-1299. http://dx.doi.org/10.3168/jds.S0022-0302(98)75691-7. PMid:9621231.

National Mastitis Council 1999. Laboratory handbook on bovine mastitis. Nat. Mastits Council (NCM), Arlington.

Nguyen D.A. \& Neville M.C. 1998. Tight junction regulation in the mammary gland. J. Mammary Gland Biol. Neoplasia 3(3):233-246. http://dx.doi. org/10.1023/A:1018707309361. PMid:10819511.
Nia E.F., Nikkhah A., Rahmani H.R., Alikhani M., Alipour M.M. \& Ghorbani G.R. 2010. Increased colostral somatic cell counts reduce pre-weaning calf immunity, health and growth. J. Anim. Physiol. Anim. Nutr., Berlin, 94(5):628-634. http://dx.doi.org/10.1111/j.1439-0396.2009.00948.x. PMid:20050956.

Pessoa R.B., Blagitz M.G., Batista C.F., Santos B.P., Parra A.C., Souza F.N. \& Libera A.M.M.P.D. 2012. Avaliação da apoptose de leucócitos polimorfonucleares CH138+ em leite bovino de alta e baixa contagem de células somáticas: dados preliminares. Arq. Bras. Med. Vet. Zootec. 64(3):533-539. http:// dx.doi.org/10.1590/S0102-09352012000300002.

Quinn P.J., Markey B., Carter M.E., Donnelly W.J. \& Leonard F.C. 2005. Microbiologia Veterinária e Doenças Infecciosas. Artmed, Porto Alegre. 512p.

Raimondo R.F.S., Miyiashiro S.I., Mori C.S. \& Birgel Junior E.H. 2013. Proteínas do soro lácteo de vacas da raça Jersey durante a lactação. Pesq. Vet. Bras. 33(1):119-125. http://dx.doi.org/10.1590/S0100-736X2013000100022.

Reis J.F., Leite R.F., Silva C.P.C., Baccili C.C., Melville P.A., Benites N.R. \& Gomes V. 2016. Contagem de células somáticas como indicador de infecção mamária em vacas periparturientes. Braz. J. Vet. Res. Anim. Sci. 53(2):161-168. http://dx.doi.org/10.11606/issn.1678-4456.v53i2p161-168.

Rocha T.G. 2010. Avaliação da transferência de imunidade passiva em bezerros de vacas da raça Canchim. Dissertação de Mestrado, Medicina Veterinária, Faculdade de Ciências Agrárias e Veterinárias, Universidade Estadual Paulista, Jaboticabal, SP. 108p.

Sant'Ana V.A.C. 2004. Proteinograma do leite de vacas: padrões e variabilidade. Tese de Doutorado, Clínica Veterinária, Faculdade de Medicina Veterinária e Zootecnia, USP, São Paulo, SP. 161p.

Sargeant J.M., Leslie K.E., Shirley J.E., Pulkrabek B.J. \& Lim G.H. 2001. Sensitivity and specificity of somatic cell count and california mastitis test for identifying intramammary infection in early lactation. J. Dairy Sci. 84(9):2018-2024 http://dx.doi.org/10.3168/jds.S0022-0302(01)74645-0. PMid:11573781.

Schrick F.N., Hockett M.E., Saxton A.M., Lewis M.J., Dowlen H.H. \& Oliver S.P. 2001. Influence of subclinical mastitis during early lactation on reproductive parameters. J. Dairy Sci. 84(6):1407-1412. http://dx.doi.org/10.3168/jds. S0022-0302(01)70172-5. PMid:11417699.

Shamay A., Homans R., Fuerman Y., Levin I., Barash H., Silanikove N. \& Mabjeesh S.J. 2005. Expression of albumin in nonhepatic tissues and its synthesis by the bovine mammary gland. J. Dairy Sci. 88(2):569-576. http://dx.doi. org/10.3168/jds.S0022-0302(05)72719-3. PMid:15653522.

Sordillo L.M., Nickerson S.C. \& Akers R.M. 1989. Pathology of Staphylococcus aureus mastitis during lactogenesis: relationships with bovine mammary structure and function. J. Dairy Sci. 72(1):228-240. http://dx.doi.org/10.3168/ jds.S0022-0302(89)79101-3. PMid:2925949.

Urech E., Puhan Z. \& Schallibaum M. 1999. Changes in milk protein fraction as affected by subclinical mastitis. J. Dairy Sci. 82(11):2402-2411. http:// dx.doi.org/10.3168/jds.S0022-0302(99)75491-3. PMid:10575607.

Voltolini T.V., Santos G.T.D., Zambom M.A., Ribas N.P., Müller E.E., Mamasceno J.C., Ítavo L.C.V. \& Veiga D.R.D. 2001. Influência dos estádios de lactação sobre a contagem de células somáticas do leite de vacas da raça holandesa e identificação de patógenos causadores de mastite no rebanho. Acta Sci. Vet. 23(4):961-966.

Zar J.H. 1999. Biostatistical Analysis. 4th ed. Prentice-Hall, New Jersey. 930p. 